\title{
Gambaran Kasus Spina Bifida di RSUD Arifin Achmad Provinsi Riau Periode 2015-2017
}

\author{
Syntha Novianti Rahmad, ${ }^{1 *}$ Andrea Valentino, ${ }^{2}$ Huriatul Masdar ${ }^{3}$
}

\begin{abstract}
Spina bifida is a fault in the development of spine and the bones around until it leaves gap or defect in the spine. About 36 cases of spina bifida were involved in this research. The characteristis of spina bifida patients, mostly occurs at the patients at the age of $>28$ days $(83,3 \%)$. Most of them were male $(52,8 \%)$. The most frequent spina bifida patients were the second child $(44,4 \%)$ and location where spina bifida occurs were at the lumbosakral $(72,2 \%)$. Classified into spina bifida aperta type (86,1\%). The highest age of patients' mother suffering from spina bifida was at the age of $20-40$ $(80,6 \%)$. In general, rupture didn't occur on spina bifida patients (94.4\%). The weightof spina bifida patients were between 2.500-4.000gr (94,4\%) and they didn't have other congenital abnormalities $(47,2 \%)$. The most gestational age of spina bifida patients' mothers when giving birth were, is at 28-40 weeks (94.4\%).
\end{abstract}

Keywords: aperta, occult, spina bifida

Angka kematian anak yang disebabkan kelainan yang dibawa sejak lahir di dunia pada tahun 2002-2012 menurut WHO berada pada peringkat kelima kematian dari 1000 kelahiran. ${ }^{1,2}$ Menurut Kementrian Kesehatan, ada tujuh kelainan yang sering muncul pada kasus kematian bayi yaitu kelainan sistem syaraf (spina bifida, anenchepaly, meningo/encephalocele dan hydrocepalus), kelainan mata (katarak kongenital), kelainan bibir dan langit-langit (celah langit-langit saja, celah bibir saja, dan celah bibir dan langit-langit) kelainan genitalia dan saluran kemih (hypospadia dan epispadia), kelainan sistem muskulo-skeletal (talipes equinovarus, dan reduksi extremitas), kelainan saluran gastrointestinal (atresia ani dengat atau tanpa fistula), serta kelainan lain seperti omphalocele, gartroschizis, dan kembar siam. ${ }^{3}$

Salah satu kelainan kongenital yang biasa terjadi ialah spina bifida. ${ }^{4}$ Spina bifida adalah gangguan kompleks neuroembriologi pada janin akibat tidak

\footnotetext{
* Corresponden author: email ssynthanoviantirahmad @gmail.com

1 Fakultas Kedokteran Universitas Riau, Pekanbaru, Riau, Indonesia

2 KJFD/KSM Bedah Divisi Bedah Saraf Fakultas Kedokteran Universitas Riau/ RSUD Arifin Achmad Provinsi Riau, Indonesia

3 KJFD Histologi Fakultas Kedokteran Universitas Riau Pekanbaru, Riau, Indonesia
}

sempurnanya penutupan tabung saraf posterior (biasanya saat usia kandungan 22 hari) yang berujung terjadinya defek pada sumsum tulang belakang dan merupakan anomali dalam pembentukan tulang belakang. 5,6

Spina bifida secara umum juga dibagi menjadi 2 jenis, yaitu spina bifida aperta (SBA) dan spina bifida occulta (SBO). ${ }^{7}$ Dikutip dari O’Hara (2013) spina bifida biasanya diikuti beberapa gejala umum seperti gangguan mobilitas dan hidrosefalus. ${ }^{8}$ Selain diikuti gangguan mobilitas dan hidrosefalus, pada beberapa kasus spina bifida juga memiliki gejala yang dapat dilihat secara fisik, yaitu munculnya tonjolan pada area tulang belakang. ${ }^{9}$ Tonjolan ini disebabkan oleh gagalnya penutupan tabung saraf posterior yang memicu keluarnya sumsum tulang belakang dari tabung tersebut, ditambah lagi matinya saraf akibat toksisitas dari cairan ketuban, sehingga muncul tonjolan permukaan kulit di area tulang belakang penderita. ${ }^{10}$

Spina bifida merupakan kasus yang cukup sering terjadi di dunia. Di Timur Tengah khususnya Sudan, dari 137 kejadian spina bifida terdapat 55,5\% pasien laki-laki dan 44,5\% pasien perempuan. ${ }^{11}$ Angka kematian anak akibat kelainan kongenital di Indonesia, yaitu sebanyak 59,3\% per 1000 kelahiran hidup, atau sekitar 295.000 kelainan bawaan 
pertahun, 22,3\% nya adalah spina bifida dan gangguan sistem saraf lainnya. ${ }^{3}$ Menurut Laksono (2010) kasus spina bifida di RSUD Serang Jawa Barat tercatat kurang dari 10 kasus dalam periode tahun 2007 dan 2010. ${ }^{12}$ Di Rumah Sakit Pendidikan Fakultas Kedokteran YARSI, tercatat 11,2 kejadian kelainan kongenital dari 1000 kelahiran, dimana 40\% nya adalah spina bifida. ${ }^{13}$

Data Kementrian Kesehatan RI dari 13 percontohan di 9 provinsi di Indonesia sejak September 2014, kasus spina bifida dan kelainan sistem saraf lainnya termasuk kasus dengan persentase kejadian terbesar di Indonesia, dengan persentase sebesar 22,3\% dari 231 bayi dengan kelainan bawaan. ${ }^{3}$ Penelitian ini bertujuan untuk melihat profil kasus spina bifida yang terjadi RSUD Arifin Achmad Provinsi Riau pada periode 2015 - 2017.

\section{METODE}

Penelitian ini bersifat deskriptif menggunakan data rekam medik pasien spina bifida di RSUD Arifin Achmad Provinsi Riau periode Januari 2015 Desember 2017 dengan teknik pengambilan sampel yang digunakan adalah metode total sampling.

\section{HASIL}

Sampel penelitian ialah 36 rekam medik yang disesuaikan dengan kode ICD-10 (International Classification of Diseases-10) yaitu Q05.0, atau spina bifida di RSUD Arifin Achmad Provinsi Riau periode Januari 2015 - Desember 2017.

Tabel 1. Gambaran kasus spina bifida di RSUD Arifin Achmad Provinsi Riau periode Januari 2015 Desember 2017

\begin{tabular}{|c|c|c|}
\hline Variabel & Frekuensi & Persentase $(\%)$ \\
\hline \multicolumn{3}{|l|}{ Usia pasien $(n=36)$} \\
\hline 0-7 hari & 4 & 11,1 \\
\hline $8-28$ hari & 2 & 5,6 \\
\hline$>28$ hari & 30 & 83,3 \\
\hline \multicolumn{3}{|l|}{ Jenis kelamin $(\mathrm{n}=36)$} \\
\hline Laki-laki & 19 & 52,8 \\
\hline Perempuan & 17 & 47,2 \\
\hline \multicolumn{3}{|l|}{ Urutan kelahiran $(\mathrm{n}=36)$} \\
\hline Anak ke 1 & 11 & 30,6 \\
\hline Anak ke 2 & 16 & 44,4 \\
\hline Anak ke $=3$ & 9 & 25 \\
\hline \multicolumn{3}{|l|}{ Jenis penyakit $(\mathrm{n}=36)$} \\
\hline Spina bifida aperta & 31 & 86,1 \\
\hline Spina bifida okulta & 5 & 13,9 \\
\hline Kelompok usia ibu $(\mathrm{n}=36)$ & 0 & 0 \\
\hline$<20$ tahun & 29 & 80,6 \\
\hline 20-40 tahun & 29 & $\begin{array}{l}00,0 \\
194\end{array}$ \\
\hline$>40$ tahun & & \\
\hline \multicolumn{3}{|l|}{ Lokasi penyakit $(\mathrm{n}=36)$} \\
\hline Sacral & 6 & 16,7 \\
\hline Lumbosacral & 26 & 72,2 \\
\hline Lumbal & 4 & 11,1 \\
\hline Torakolumbal & 0 & 0 \\
\hline \multicolumn{3}{|c|}{ Adanya ruptur atau tidak $\quad(n=36)$} \\
\hline Ruptur & 2 & 5,6 \\
\hline Tidak ruptur & 34 & 94,4 \\
\hline \multicolumn{3}{|c|}{ Berat badan pasien saat lahir $(\mathrm{n}=36)$} \\
\hline$<2.500 \mathrm{gr}$ & 2 & 5,6 \\
\hline $2.500 \mathrm{gr}-4.000 \mathrm{gr}$ & 34 & 94,4 \\
\hline$>4.000 \mathrm{gr}$ & 0 & 0 \\
\hline \multicolumn{3}{|l|}{ Usia kehamilan ibu } \\
\hline 0-12 minggu & 0 & 0 \\
\hline 13-27 minggu & 0 & 0 \\
\hline 28-40 minggu & 34 & 94,4 \\
\hline$>40$ minggu & 2 & 5,6 \\
\hline
\end{tabular}


Berdasarkan tabel 1, pasien spina bifida yang tercatat dalam status rekam medik RSUD Arifin Achmad Provinsi Riau periode Januari 2015 Desember 2017 menurut usia, pasien terbanyak pada kasus spina bifida terdapat dalam rentang usia $>28$ hari, yaitu sebanyak 30 orang $(83,3 \%)$, dan paling sedikit pada kelompok usia 8-28 hari sebesar 2 orang (5,6\%). Jenis kelamin pasien spina bifida tertinggi adalah laki-laki, dengan jumlah sebanyak 19 orang $(52,8 \%)$. Sedangkan jenis kelamin pasien spina bifida terendah adalah perempuan, dengan jumlah sebanyak 17 orang $(47,2 \%)$. Urutan kelahiran yang tertinggi adalah anak ke 2 sebanyak 16 orang $(44,4 \%)$. Sedangkan urutan kelahiran terendah ialah anak ke e"3 dengan jumlah 9 orang (25\%).

Jenis penyakit spina bifida terbanyak adalah spina bifida aperta dengan jumlah sebanyak 31 pasien (86,1\%). Jenis penyakit spina bifida terendah adalah spina bifida okulta sebanyak 5 pasien (13,9\%). Berdasarkan usia ibu, kelompok usia ibu terbanyak adalah 20-40 tahun sebanyak 29 orang (80,6\%). Usia ibu paling sedikit yang ditemukan ialah $>40$ tahun sebanyak 7 orang $(19,4 \%)$.
Lumbosacral merupakan lokasi terbanyak penderita spina bifida dengan jumlah 26 kasus (72,2\%), 6 kasus ditemukan di sacral $(16,7 \%)$, dan paling sedikit di temukan di lumbal dengan 4 kasus $(11,1 \%)$, sedangkan di torakolumbal tidak di temukan sama sekali.

Kondisi pasien spina bifida yang mengalami ruptur sebanyak 2 pasien (5,6\%), sedangkan 34 pasien $(94,4 \%)$ tidak mengalami ruptur. Berat badan pasien spina bifida saat lahir tertinggi adalah $2.500 \mathrm{gr}$ - 4.000gr sebanyak 34 orang $(94,4 \%)$, yang paling sedikit adalah $<2.500$ gr dengan jumlah sebanyak 2 orang (5,6\%). Sedangkan berat badan pasien spina bifida saat lahir $>4.000$ gr tidak memiliki kelainan spina bifida.

Usia kehamilan ibu pasien spina bifida saat melahirkan yang tercatat dalam status rekam medik RSUD Arifin Achmad Provinsi Riau periode Januari 2015 - Desember 2017 terbanyak (poin 10) terbanyak adalah 20-40 minggu dengan 34 orang $(94,4 \%)$, paling sedikit $>40$ minggu sebesar 2 orang (5,6\%), sedangkan usia kehamilan 0-12 minggu dan 13-27 minggu tidak memiliki anak dengan kelainan spina bifida.

Tabel 2. Kelainan bawaan lain yang menyertai

\begin{tabular}{lcc}
\hline \multicolumn{1}{c}{ Variabel } & Frekuensi & Persentase $(\%)$ \\
\hline Kelainan bawaan lain $(\mathrm{n}=36)$ & & 5,6 \\
a. Anal defects & 2 & 2,8 \\
b. Cardiac defects & 1 & 0 \\
c. Tracheosophageal fistula & 0 & 2,8 \\
d. Esophageal defects & 1 & 5,6 \\
e. Renal anomalies & 2 & 2,8 \\
f. Limb defects & 1 & 11,1 \\
g. Hidrosefalus & 4 & 5,6 \\
h. Ensefalokel & 2 & 8,3 \\
i. Limb defects dan Hidrosefalus & 3 & 8,3 \\
j. Limb defects dan Cardiac defects & 3 & 47,2 \\
k. Tidak ada & 17 & \\
\hline
\end{tabular}

Berdasarkan tabel 2, pasien yang tidak memiliki kelainan bawaan lain adalah pasien terbanyak pada kasus spina bifida di RSUD Arifin Achmad Provinsi Riau periode terbanyak penderita spina bifida periode Januari 2015 - Desember 2017 dengan jumlah 47 kasus (47,2\%), 4 kasus ditemukan hidrosefalus (11,1\%), 3 kasus di temukan di limb defects dan hdrosefalus serta di limb defects dan cardiac defects $(11,1 \%), 2$ kasus masing-masing di temukananal defects, renal defects,dan ensefalokel $(11,1 \%)$ dan paling sedikit di temukan multiple kongenital dengan 1 kasus (2,8\%), sedangkan anal defects, cardiac defects, tracheoesophageal fistula, esophageal defects, renal anomalies dan 
limb defectstidak dimiliki oleh pasien spina bifida.

\section{PEMBAHASAN}

Pada penelitian ini ditujukan untuk mengetahui karakteristik demografi meliputi usia, jenis kelamin, urutan keturunan, jenis penyakit spina bifida, kelompok usia ibu, lokasi penyakit spina bifida, ada atau tidaknya ruptur pada spina bifida, berat badan, dan kelainan bawaan yang menyertai pada pasien spina bifida di RSUD Arfifin Achmad Provinsi Riau periode Januari 2015 - Desember 2017. Pada penelitian ini didapatkan angka kejadian sebanyak 36 kasus spina bifida dimana 5 kasus pada tahun 2015, 13 kasus pada tahun 2016 dan 18 kasus pada tahun 2017. Dari 36 kasus diantaranya 22 kasus mendapatkan tindakan bedah selama periode januari 2015 - desember 2017.

Pada data yang diperoleh Kementerian Kesehatan RI menunjukan bahwa di Indonesia angka kematian anak akibat kelainan kongenital yaitu sebanyak 59,3\% per 1000 kelahiran hidup, atau sekitar 295.000 kelainan bawaan pertahun, dimana 22,3\% nya adalah spina bifidadan gangguan sistem saraf lainnya. ${ }^{3}$ Menurut data dari Direktorat Kesehatan Keluarga (2017), sekitar 50\% penyakit kelainan bawaan tidak diketahui penyebabnya, namun ada sejumlah penyebab dan faktor resiko yang di ketahui yaitu faktor sosioekonomi, genetik, infesi, lingkungan, dan status gizi ibu. ${ }^{14}$

Pada data penelitian ini secara sosio demografis diperoleh distribusi data berdasarkan kelompok usia pasien terbanyak pada kasus spina bifida terdapat dalam rentang usia $>28$ hari, yaitu sebanyak 30 orang (83,3\%), dan paling sedikit pada kelompok usia 8 28 hari sebesar 2 orang (5,6\%).Diperoleh pula distribusi data berdasarkan jenis kelamin pada penelitian ini, diketahui jenis kelamin pasien spina bifida laki-laki lebih banyak ditemukan dengan jumlah 19 orang (52,8\%) dibandingkan perempuan dengan jumlah sebanyak 17 orang (47,2\%).

Penelitian yang dilakukan oleh Salim $\mathrm{dkk}^{11}$ menunjukan bahwa di negara Timur khususnya Sudan, dari 137 kejadian spina bifidaterdapat 55,5\% pasien laki-laki dan $44,5 \%$ pasien perempuan. Penilitian yang dilakukan oleh Evan G dkk didapatkan bahwa pasien dengan diagnosis spina bifida lebih banyak berjenis kelamin laki-laki yaitu 48 orang
(72,7\%). ${ }^{15}$ Bayi laki-laki cenderung lebih rentan dibandingkan bai perempuan. Secara biologis bayi perempuan mempunyai keunggulan fisiologi pada tubuhnya jika dibandingkan laki-laki, bayi perempuan memiliki kromosom XX sedangkan laki-laki XY. Jika salah satu dari kromosom X pada bayi perempuan kurang baik maka dapat digantikan oleh kromoson $\mathrm{X}$ yang lainnya, sedangkan jika salah satu kromosom pada bayi laki-laki kondisinya kurang baik, maka tidak ada kromosom pengganti yang dapat menggantikan kromosm yang rusak. ${ }^{14}$

Pada data penelitian juga diperoleh distribusi data berdasarkan gambaran berat badan pada pasien spina bifida periode Januari 2015 - Desember 2017 adalah 2.500gr-4.000gr dengan 34 orang, dimana hal ini menunjukan bahwa hampir seluruh populasi penelitian yang mengalami spina bifida memiliki berat badan normal.

Urutan keturunan pasien spina bifida tertinggi adalah anak kedua (2) sebanyak 16 orang $(44,4 \%)$ sedangkan urutan kelahiran spina bifida terendah ialah diatas anak kedua $(\geq 3)$ dengan jumlah 9 orang (25\%). Menurut penelitian Rani Agrraini (2015) resiko dari anak kedua dari orang tua dengan anak pertama menderita spina bifida meningkat $2-5 \% .{ }^{17}$

Pada hasil distribusi data diatas menunjukan bahwa terdapat perbedaan antar urutan kelahiranpaisen spina bifida dengan penelitian yang dilakukan oleh Copp A dkk yang menunjukan bahwa risiko untuk saudara kandung (anak kedua) akan meningkat 2-5\%.Peningkatan tersebut mencapai 20 hingga 50 kali lipat dibandingkandengan prevalensi populasi umum. Anak kedua dan ketigamenunjukkan risiko kambuh yang lebih tinggi daripada anak pertama, tetapi masih lebih tinggi daripada yang tidak terkaitindividu. ${ }^{10}$ Pada wanita tertentu, risiko kekambuhan penyakit spina bifida akan meningkat dari 3\% menjadi 10\% setelah kehamilan anak pertama. ${ }^{18} \mathrm{Hal}$ ini dikarenakan spina bifida merupakan kelainan kongenital yang bersifat multifactorial. ${ }^{17}$

Telah lama diketahui bahwa penyakit yang diakibatkan oleh faktor genetik dan non-genetik sangat banyak terjadi khususnya terhadap spina bifida. Menurut survei prevalensi pada 1960-an, di South Wales, Glasgow, dan London, Faktor genetik diperkirakan berjumlah 60-70\% yang diturunkan oleh saudara kandung (anak pertama). ${ }^{18}$ 
Pada data penelitian ini secara klinis demografis, diperoleh gambaran jenis penyakit pasien spina bifida tertinggi ialah spina bifida aperta, dengan jumlah sebanyak 31 pasien $(86,1 \%)$ sedangkan yang terendah ialah spina bifida okulta sebanyak 5 pasien (13,9\%). Menurut penelitian Achmad Adam, 95\% jenis penyakit yang di derita pasien spina bifida adalah myelomeningocele (aperta). ${ }^{19}$

Kelainan yang sering terjadi pada pasien spina bifida adalah myelomeningocele. Hal ini disebabkan oleh dimana terjadi hernia korda spinalis dan akar saraf membentuk kantung yang juga berisi meninges. Kantung ini berprotrusi melalui vertebra dan defek muskulokutaneus. Korda spinalis sering berakhir pada kantung ini dan terbuka kemudian keluar disertai ekspose dari kanalis sentralis. ${ }^{17}$ Menurut penelitian Salim dkk keterlambatan diagnosis pada pasien spina bifida dan ineksi preoperatif dikaitkan dengan mortalitas yang tinggi menyebabkan terjadinya spina bifida jenis myelomeningocele. ${ }^{11}$

Usia kehamilan ibu pasien spina bifida saat melahirkan berdasarkan rekam medis periode Januari 2015 - Desember 2017 didapatkan 34 pasien kehamilan 28-40 minggu (94,4\%), hal ini menunjukan bahwa hampir seluruh ibu usia kehamilan normal yang mempunyai anak dengan kelainan spina bifida.

Kelompok usia ibu pasien spina bifida tertinggi ialah 20 - 40 tahunsebesar 29 orang $(80,6 \%)$ dan kelompok usia ibu terendah ialah $>40$ tahun sebesar 7 kasus (19,4\%). Pada penelitian yang dilakukan oleh Sahmat dkk menunjukan bahwa secara umum faktor terjadinya spina bifida meliputi jenis kelamin, etnis, berat badan saat lahir, dan usia ibu saat melahirkan $>20$ tahun. ${ }^{20}$ Menurut Purwaningsih (2010) salah satu faktor etiologi yang mempengaruhi terjadinya kelainan kongenital adalah umur ibu telah diketahui bahwa mongolisme lebih sering ditemukan pada bayi-bayi yang dilahirkan oleh ibu yang mendekati masa menopause. ${ }^{21}$

Hasil penelitian Conway dkk di St, Christoper's Hospital for Children tahun 2002-2007 menyatakan bahwa ibu yang melahirkan bayi dengan kelainan spina bifida terbanyak pada kelompok umur 25-34 tahun. ${ }^{22}$ Penelitian Mariska dkk didapatkan bahwa proporsi umur ibu tertinggi yang mempunyai anak dengan kelainan spina bifida adalah umur 2035 tahun (84,3\%). Tingginya proporsi umur ibu 2035 tahun karena umur tersebut merupakan kelompok usia produktif sehingga banyak ibu yang hamil dan melahirkan pada usia tersebut. ${ }^{23}$

Pada penelitian ini didapatkan 94,4\% pasien spina bifida tidak mengalami ruptur dan Lokasi penyakit pasien spina bifida pada populasi penelitian ini yang terbanyak adalah lumbosakral dengan 26 pasien (72,2\%) . Menurut penelitian Adam, 95\% jenis lokasi penyakit yang di derita pasien spina bifida terjadi di lumbal ataupun lumbosakral. ${ }^{19}$ Penelitian Salim dkk ${ }^{11}$ dari 137 kasus spina bifida sebanyak 53,3\% terjadi di lumbosakral. Menurut pendapat De jong (2004) kelainan spina bifida kebanyakan terjadi di punggung bagian bawah, yaitu daerah lumbal dan torakolumbal, karena penutupan vertebra di bagian ini yang terjadi paling lama. ${ }^{24}$

Gambaran pasien mengalami kelainan bawaan lain yaitu hidrosefalus sedangkan sedangkan 17 (47,2\%) tidak memiliki kelainan bawaan lain. Menurut penelitian O’Hara (2013) dari 170 kasus (79,5\%) pasien spina bifida mengalami hidrosefalus, ini di karenakan spina bifida biasanya diikuti beberapa gejala umum seperti gangguan mobilitas dan hidrosefalus. ${ }^{8}$ Menurut Anggraini 70-90\% biasanya pasien yang terkena spina bifida juga muncul bersamaan dengan hidrosefalus. Kedaan ini disebabkan oleh terjadi peningkatan cairan dari liquor cerebrospinal. ${ }^{17}$ Menurut Anggara (2018) bayi yang lahir dengan spina bifida kemungkinan besar disertai dengan hidrosefalus. Selain di sum-sum tulang belakang, ada kelainan tertentu pada struktur otak yang menyebabkan obstruksi kecairan cerebrospinal jalur drainase. Cerebrospinal terakumulasi dalam ventrikel di otak yang menyebabkan pembengkakan, sehingga kompresi dari jaringan sekitarnya. ${ }^{25}$

\section{SIMPULAN}

Karakteristik pasien spina bifida tertinggi terjadi pada rentang usia $>28$ hari $(83,3 \%)$ dan berjenis kelamin laki-laki (52,8\%). Pasien spina bifida tersering adalah anak kedua $(44,4 \%)$ dan termasuk jenis spina bifida aperta (86,1\%). Lokasi yang lebih sering terjadi spina bifida di lumbosacral $(72,2 \%)$. Usia ibu pasien penderita spina bifida tertinggi terjadi pada rentang usia 20-4- tahun (80,6\%). Pasien spina bifida umumnya tidak terjadi ruptur $(94,4 \%)$. Berat badan terbanyak pada pasien spina bifida adalah 
2.500-4.000 (94,4\%) dan tidak memiliki kelainan bawaan lainnya (69,4\%). Usia kehamilan ibu pasien spina bifida saat melahirkan terbanyak adalah 2840 minggu (94,4\%).

\section{DAFTAR PUSTAKA}

1. UNICEF. 2013 United Nation Inter-agency Group for Child Mortality Estmation (UN IGME). Level \& trends in child mortality. New York: UNICEF.

2. WHO. 2008. The global burden of disease : 2004 update. Geneva. USA: World Health Organization (WHO).

3. KEMENKES RI, Hari kelainan bawaan sedunia, cegah bayi lahir cacat dengan pola hidup sehat. Artikel Publikasi KEMENKES RI, 2016. Tersedia di http://www.depkes.go.id/article/print/ 16030300001/3-maret-hari-kelainan-bawaansedunia-cegah-bayi-lahir-cacat-dengan-polahidup-sehat-.html diakses tanggal 5 Februari 2018.

4. WHO, CDC, ICBDSR, Birth defect surveillance: Atlas of selected congenital anomalies. WHO Library Cataloguing in Publication data,2014.

5. Abdoerrachman, A. 1985. Buku Kuliah Ilmu Kesehatan Anak Volume 2. Jakarta: Penerbit Infomedika Jakarta.

6. Liptak, G Samra, A. 2010. Optimizing health care for children with spina bifida. Developmental Disabilities Research Reviews, 16(1): 66-75.

7. Volpe, J.J. 2010. Neurology of the newborn. Philadelphia: Saunders, 2010.

8. O’Hara, Lauren K, Holmbeck, Grayson N. 2013. Executive function and parenting behaviour in association with medical adherence and autonomy among youth with spina bifida. Journal of Pediatric Psychology. 1(1) : 675-687.

9. Jobe, J. H. 2002. Fetal Surgery for Myelomeningocele. The New England Journal of Medicine. 37(4) : 230-231.

10. Agopian, A. J, Tinker, S. C, Lupo, P. J, Canfield, M. A, Mitchell, L. E. 2013. Proportion of neural tube defect. Res. A Clin. Mol. Teratol 97(1) : 4246.
11. Salim, Darrag, Abubakar. 2016. Spina bifida in Sudan. Journal of Neurology and Neuroscience, 2(1) : 1-8.

12.Zulkarnaen, N. 2010. Asuhan Keperawatan Spina Bifida. UNAIR.

13.Mustofa, Samsul, Sumiarsih, TWikaningrum, Riyani. 2009. Prevalensi bayi lahir cacat (malformasi kongenital) di RS Pendidikan FK YARSI. Jurnal Kedokteran YARSI. 1(1) : 101110.

14.KEMENKES RI Kondisi Birth Defects di Indonesia, Artikel Publikasi oleh Direktorat Kesehatan Keluarga,2017. Tersedia di http:// kesga.kemenkes.go.id/berita-lengkap.php?id=21 diakses pada tanggal 27 Maret 2019

15.Evan, G., Wiliar, Umboh. 2016. Faktor risiko yang berhubungan dengan kejadian kelainan bawaan pada neonatus di RSUP Prof Dr. R. D. Kandou Manado. UNSRAT

16. Azizah, I., Kasmini. 2016. Kematian neonatal di kabupaten Grobogan. UNNES

17. Anggraini, R. 2015. Spina Bifida. Tersedia di https://www.academia. edu/17652305/ spina bifida diakses pada tanggal 27 Maret 2019

18. Copp A, Adzick S, Chitty L, Fletcher J, Holbeck G, Shaw G, et al. Spina Bifida. Nat Rev Dis Primers. 2015;1:3

19.Adam, A. 2015. Kelainan - kelainan perkembangan susunan Saraf. UNPAD

20.Sahmat A, Gunasekaran R, Mohd-Zin SW, Balachandran L, Thong M, Engkasan J, et al. The prevalence and distribution of spina bifida in a single major referral center in malaysia. Front Pediatr. 2017;5(237):2

21.Purwaningsih,W. 2010. Asuhan Keperawatan Maternitas. Yogyakarta: ISBN

22.Conway,D. H. 2008. Prevalence of congenital anomalies in Infants with in utero exposure to antiretrovirals: IMPAACT P1025. National Institute of Health Philladelphia.

23.Mariska, S., Muda, S., Jemadi. 2012. Karakteristik ibu yang melahirkan bayi dengan kelainan kongenital di RSUD DR.Pringadi Medan. USU 
Syntha Novianti Rahmad, dkk, Gambaran Kasus Spina Bifida di RSUD Arifin Achmad Provinsi Riau

24.De Jong, Wim. 2004. Sistem Saraf. Buku Ajar Ilmu Bedah. Edisi 2. Jakarta: EGC
25. Anggara, Y., 2018. Spina - Bifida. Tersedia di https://id.scribd.com/ document/369929091/ 130945885-Spina-Bifida diakses pada tanggal 27 Maret 2019 